\title{
(CO)VARIANCE STRUCTURES AND GENETIC PARAMETERS OF RETAINED PLACENTA AND STILLBIRTH FOR A FRIESIAN HERD USING MULTI-PARITY THRESHOLD MODELS.
}

\author{
Hanaa Abdelharith
}

Animal Production Research Institute, Agricultural Research Center, Dokki, Giza, Egypt

Received: 10/3/2019 Accepted: 10/6/2019

\section{SUMMARY}

(Co)variance components were estimated for retained placenta $(R P)$ and stillbirth $(S B)$ for a Friesian herd to study the (co)variance structures of these traits in the first three lactations. Genetic parameters and predicted breeding values (BV) were also estimated. (Co)variance components and estimated genetic parameters were derived from 3336 calving records of a Friesian herd raised at Sakha experimental farm belonging to Animal Production Research Institute (APRI) in Egypt.

Retained placenta and SB traits were treated as different and correlated traits for the first three lactations using threshold multiple trait models. A sire-maternal grand sire (MGS) model for SB was applied in order to account for direct and maternal effects of this trait and including the relationships among direct and maternal effects, while a sire model was fitted for RP.

Genetic and phenotypic variances of RP had an increasing trend through the first three lactations. Also, covariances among lactations had the same increasing trend. Heritability estimates were 0.23, 0.28 and 0.31 for the first three lactations, respectively. Genetic correlations were 0.56, 0.57 and 0.67 between first and second, first and third and second and third lactations, respectively. Means of BV estimates for RP in the first three lactations were almost zero with negative signs, while rank correlation of $B V$ estimates among lactations were $0.69,0.68$ and 0.56 , respectively.

Direct genetic variance components of $S B$ had an increasing trend from the first to the third lactations. Rate of increase of variance was higher (27\%) between second and third lactations. Maternal genetic variance components were higher than the direct components. Direct genetic variance of heifers was lower than that of cows in the second and third lactations while maternal genetic variance was higher than of cows in the same lactations. All genetic covariances between direct and maternal effects were favourable, positive and the directmaternal genetic correlation estimates ranged from 0.20 to 0.75 .

Direct heritability estimates of $S B$ in the first three lactations were $0.28,0.25$ and 0.23 , respectively while maternal heritability estimates were $0.39,0.34$ and 0.35 , respectively.

Direct genetic correlation estimates were 0.63, 0.42 and 0.71 between first and second, first and third and second and third lactations, respectively while maternal genetic correlation estimates were 0.68, 0.36 and 0.46 , respectively.

Means of $B V$ estimates of $S B$ in the first three lactations were all negative and ranged from -0.499 to -2.477 for all direct and maternal sires and MGS. Positive and from moderate to high rank correlation estimates were obtained between lactations BVs ranging from 0.24 to 0.97 .

Moderate heritability estimates of RP and SB suggest that selection against these traits and a chance of genetic improvement in the herd are possible. Multi-parity models utilized accounted for the (co)variance among the different lactations. Also, the genetic correlation estimates between lactations within traits indicated that RP and SB are different traits through the first three lactations. Rank correlations of direct evaluation of sires between lactations were significant and moderate which justify the importance of the multi-parity evaluation.

Keywords: Functional traits, retained placenta, stillbirth, multi-parity model, (co)variance structure, genetic parameters, breeding values and Friesian

\section{INTRODUCTION}

National breeding programs and evaluations are concerning with functional traits that reduce cost rather than increase income. Retained placenta (RP) and stillbirth (SB) are of among the most frequent functional traits in dairy cattle. Eaglen et al. (2013) reported that national breeding indices are concerning with including functional traits. As a fertility-related trait, RP can decrease cow fertility and increase calving interval which are of economic importance, Hauggard and Heringstad (2015).

Koeck et al. (2014) confirmed that selection against RP and other fertility-related traits will result in improvement of fertility. Hossein-Zadeh (2011) stated that breeding programs shifted focus from selection of production traits to functional traits in dairy cows. Stillbirth is one of the traits that is included regularly in the national genetic evaluations, Wiggans et al. (2008), Eaglen et al. (2011) and Liu et 
al. (2012). A national genetic evaluation for SB using sire-maternal grandsire (S-MGS) model was applied in 2006 in the USA and the required genetic parameters were estimated, (Cole et al.2007a).

Haugaard and Heringstad (2015) reported that as some of the fertility-related traits increase in frequency in the later lactations, it may be advantageous to use multiple lactations in the genetic evaluation process. Heringstad et al. (2005) reported that RP genetically is not the same trait across the first three lactations. Philipson and Steinbock, (2003) reported that SB is genetically different among different lactations. Wiggans et al. (2008) reported that evaluation for SB by parity should increase evaluation accuracy. Liu et al. (2012) developed a multi-parity calving animal model with correlated direct and maternal effects for the genetic and genomic evaluation of SB and other calving traits. The authors treated the first three lactations as genetically distinct traits in this new calving model.

Eaglen et al. (2012) concluded that threshold models can be more appropriate for the analysis of categorical traits. Steinbock et al., (2003), Hansen et al. (2004) and Swalve et al. (2006) reported that threshold models exhibit considerable more genetic variation.

The sire-MGS model provides evaluations that include both direct (sire) and maternal SB effects and adjusts sire effects for differences in the maternal SB ability of their mates, (Cole et al., 2007b). Eaglen et al. (2012) demonstrated that the Sire-MGS model is the most appropriate model for the estimation of genetic parameters for calving traits and yield sire and maternal grandsire (co)variances. Eaglen et al. (2013) recommended including sire of calf effect so that maternal effects can be separated from direct effect.
The main objectives of this research were to estimate variance and covariance components of RP and SB to study the (co)variance structures in the first three lactations, to estimate their genetic parameters for the first three lactations and to estimate the breeding values and rank correlation among sires and MGS in the first three lactations of a Friesian herd in Egypt.

\section{MATERIALS AND METHODS}

Data:

This research concerned only with the first three lactation records that collected from a Friesian herd located in Sakha Experimental Station, which belongs to the Animal Production Research Institute (APRI), Egypt. The herd was first imported from the Netherlands in 1959 as 948 pregnant heifers and 19 bulls. A total of 3336 records were collected from 1112 cows, daughters of 176 sires, 752 dams and 89 maternal grandsires along 38 years. Cows were artificially inseminated with tested bulls. Information about pedigree, calving and fertility traits, service sire, age of cows and calving dates were included in the data set. Traits studied were retained placenta and stillbirth as two of the most frequent functional traits. The traits were defined as binary traits (0 and 1). Months of calving were grouped in two seasons as from December to April is season 1 and from May to November is season 2 . Age at first calving was restricted to be not younger than 23.5 month. Sex of calf was defined as two levels (male and female calves). The data structure and incidences of retained placenta (RP) and stillbirth (SB) are presented in table 1.

Table 1. Data structure and incidence of RP and SB in the first three lactations of Friesian cows

\begin{tabular}{lccc}
\hline & Lactation & Lactation 2 & Lactation 3 \\
\hline RP \% & 7.0 & 6.6 & 8.9 \\
SB \% & 7.4 & 3.7 & 1.6 \\
Age at calving, month & 32.8 & 49.1 & 64.5 \\
No. of cows for RP trait & 1063 & 807 & 563 \\
No. of sires of cows & 160 & 144 & 129 \\
No. of sires of calves & 167 & 153 & 141 \\
No. of maternal grandsires (MGS) & 176 & 174 & 162 \\
\hline
\end{tabular}

Herd:

The experimental animals were kept under the routine feeding and managerial system applied in Sakha experimental farm. Cows were kept in loose open yards with about $65 \%$ of the area shaded by roofs of 3.7 meter height. Cows were observed for mounting activity, vulvar mucous discharge, restlessness and other clinical signs of heat. Cows were inseminated artificially using frozen semen locally prepared in the International Livestock Management Training Center at Sakha. According to the farm routine, it was not allowed to inseminate a cow earlier than forty days after calving. Daily allowances of feed were offered in amounts to cover the animal requirements according to their milk production, body weight and the reproductive status recommended by APRI.

\section{Statistical models and analyses:}

Variance and covariance components and genetic parameters were estimated for both of RP and SB in the first three lactations using the following models:

\section{Sire model for RP:}

Retained placenta was analyzed for the 3 lactations as multi-parity correlated traits in a 3-trait threshold sire model. The model included the systematic effects of age at calving (in months), year of calving (38 levels), season of calving (2 levels) and sex of calf ( 2 levels) and the random additive genetic sire effect, and random residual effect which 
was set equal to 1 in the analysis as it is a customize for threshold models. Variance components, genetic parameters and breeding values were obtained from the following sire model:

$$
\begin{gathered}
\mathbf{y}=\mathbf{X} \boldsymbol{\beta}+\mathbf{Z}_{\mathbf{s}} \mathbf{s}+\mathbf{e} \\
\text { Where, }
\end{gathered}
$$

$\mathbf{y}$ is the vector of observations of the traits;

$\mathbf{X}$ is the incidence matrix relating the observations to their respective non-genetic fixed effects;

$\boldsymbol{\beta}$ is the vector of an overall mean and non-genetic fixed effects in the model with association matrix $\mathrm{X}$;

$\mathbf{Z}_{\mathrm{S}}$ is the incidence matrix for random effects of sire;

$\mathbf{s}$ is the vector of random sire genetic effects with the as sociation matrix $\mathrm{Z}_{\mathrm{s}}$;

e is the vector of the random errors, NID $\left(0, \sigma^{2}{ }_{e} \mathrm{I}\right)$.

\section{Sire-maternal grandsire model for $S B$ :}

The SB trait was considered as a calf trait. To allow the separation of direct and maternal genetic effects, a random sire of the calf effect was included in a 3trait threshold sire-maternal grandsire threshold model. The systematic effects included were the same as of RP analysis and the random additive genetic sire of calf effect, random additive genetic maternal grandsire effect and random residual effect. Covariance between MGS and sire of calf effects was not neglected. The residual variances of each of the categorical traits were set equal to 1 . The applied sire-MGS model was:

$$
\mathbf{y}=\mathbf{X} \boldsymbol{\beta}+\mathbf{Z}_{\mathrm{s}} \mathrm{s}+\mathbf{Z}_{\mathrm{mgs}} \mathrm{mgs}+\mathrm{e}
$$

Where,

$\mathbf{y}$ is the vector of observations of the traits;

$\mathbf{X}$ is the incidence matrix relating the observations to their respective non-genetic fixed effects;

$\boldsymbol{\beta}$ is the vector of an overall mean and non-genetic fixed effects in the model with association matrix $\mathrm{X}$;

$\mathbf{Z}_{\mathbf{s}}$ is the incidence matrix for random effects of sire;

$\mathbf{s}$ is the vector of random sire of calf genetic effects with the as sociation matrix $Z_{\mathrm{s}}$;

$\mathbf{Z}_{\mathbf{m g s}}$ is the incidence matrix for random effects of mgs;

mgs is the vector of random mgs genetic effects with the association matrix $Z_{\mathrm{mgs}}$

e is the vector of the random errors, $\operatorname{NID}\left(0, \sigma^{2}{ }_{\mathrm{e}} \mathrm{I}\right)$.

The analyses of RP and SB were performed using the Multiple Trait Gibbs Sampling for Animal Models (MTGSAM) program of Van Tassel and Van
Vleck (2001) for estimation of variances and covariances by means of Bayesian methods. A Gibbs sampling chain length of 250000 rounds was run with burn in 50000 rounds. The convergence criterion used was that the change in the Log-likelihood of the function in successive iterations was less than $10^{-9}$. Genetic parameters were computed from the posterior mean of variance and covariance components obtained with the MTGSAM Package. The standard deviation of heritability estimates and genetic correlations was estimated from the solutions obtained in the iterative process (4000 solutions) using SAS (2009) package.

\section{Breeding values and ranking of bulls:}

Predicted breeding values were obtained from the previous models applied. Means of estimates were calculated and rank correlations were executed among the resulted breeding values for sires and MGS using Spearman rank correlation, SAS (2009) package.

\section{RESULTS AND DISCUSSION}

\section{Genetic, environmental and phenotypic (co)variance structures for RP:}

An increasing trend for RP genetic variance components have been found from the first lactation to the third, table 2. Rate of increase in the genetic variance components among the first three lactations were $30 \%$ from the first to the second lactation $(0.30$ to 0.39 ), and $15 \%$ from the second to the third lactation (0.39 to 0.45$)$, respectively. In general, the genetic variance increased by $50 \%$ from the first to the third lactation suggesting greater changes in heifers while growing to the third lactation. An increasing trend of the genetic variance was reported from the first to the second lactation by Lin et al. (1989) on Holstein cows with a different method of estimation.

As shown in table 2, the genetic covariance among the three lactations were the highest (0.29) between the second and the third lactations and lowest (0.19), between the first and the second lactations which may suggest that cows in the second lactation, are genetically more close to the later lactation rather than to the early lactation. Covariance also had an increasing trend which will affect the genetic correlation between lactations.

Table 2. Genetic, environmental and phenotypic (co)variance components for RP in the first three lactations

\begin{tabular}{lccc}
\hline Lactations & Genetic & Environmental & Phenotypic \\
\hline Lactation 1, variance & 0.30 & 1.0 & 1.30 \\
Lactation 2, variance & 0.39 & 1.0 & 1.39 \\
Lactation 3, variance & 0.45 & 1.0 & 1.45 \\
& & & 0.30 \\
Lactation 1,2 covariance & 0.19 & 0.11 & 0.32 \\
Lactation 1,3 covariance & 0.22 & 0.10 & 0.82 \\
Lactation 2,3 covariance & 0.29 & 0.53 & \\
\hline
\end{tabular}

The environmental variance in the three lactations were set equal to 1 , table 2 . The threshold and the residual variance are not identifiable in binary data analysis, so the residual variance is set to 1 to receive 
solutions as customary with threshold models, (Cole et al., 2007 b). Different methods and models of estimation affect the resulted estimates; Lin et al. (1989) reported 0.04 and 0.07 environmental variance components for the first and second lactations using mixed sire model. The environmental covariance was the highest between the second and the third lactation, $(0.53)$ whereas, the covariance including the first lactation were the lowest.

The phenotypic variance increased from the first to the third lactations, table 2 . The phenotypic variance and covariance had the same trend of increasing as the genetic's. The highest phenotypic covariance component $(0.82)$ was between the second and third lactations and the lowest was between the first and the second lactation (0.30). The fluctuations of incidence of RP from $7.0 \%$ to $8.9 \%$ in the third lactation could affect the phenotypic (co)variance. Abdelharith and Genena (2017) reported 2.11 for phenotypic variance component of RP for all lactations on a different data set on the same Friesian herd under this study using a threshold animal model.

Table 3 shows heritability estimates and genetic correlations of RP in the first three lactations.
Estimates of heritability increased from 0.23 in the first lactation to 0.31 in the third lactation in an increasing trend. These estimates are higher than (0.08) reported by Heringstad et al. (2005) for each of the first three lactations that were estimated on Norwegian Red cows. Many studies reported increasing trend of heritability estimates; $(0.06,0.07$ and 0.08 ) reported by Haugaard and Heringstad (2015) for the first three lactations, respectively; 0.14 and 0.28 reported by Amin et al. (2000) for the first and the second lactation respectively; 0.05 and 0.09 estimated by Lin et al. (1989) for first and second lactation, respectively. The resulted estimates of heritability were also higher than the 0.06 estimated by Heringstad (2010) for first parity, (0.14 and 0.07) of Schnitzenlehner et al. (1998) for the first and second parity, respectively and the reported estimate (0.02) of Koeck et al. (2014) for the first parity on Canadian Holstein. Abdelharith and Genena (2017) reported 0.23 and 0.26 heritability estimates for RP of all lactations using threshold animal model on the same Friesian herd under this study. The increasing trend of the genetic variance produced this trend of heritability estimates.

Table 3. Heritability estimates $\left(h^{2}\right)$, genetic $\left(r_{G}\right)$, environmental $\left(r_{E}\right)$ and phenotypic $\left(r_{P}\right)$ correlations and environmental and phenotypic proportions (Prop) for RP in the first three lactations

\begin{tabular}{cccc}
\hline Lactations & $\mathbf{h}^{\mathbf{2}}$ & Environmental Prop. & Phenotypic Prop. \\
\hline Lactation 1 & $0.23 \pm 0.13$ & $0.77 \pm 0.13$ & 1.0 \\
Lactation 2 & $0.28 \pm 0.12$ & $0.72 \pm 0.12$ & 1.0 \\
Lactation 3 & $0.31 \pm 0.14$ & $0.69 \pm 0.14$ & 1.0 \\
& $\mathbf{r}_{\mathbf{G}}$ & $\mathbf{r}_{\mathbf{E}}$ & $\mathbf{r}_{\mathbf{P}}$ \\
Lactation 1,2 & $0.56 \pm 0.42$ & $0.11 \pm 0.04$ & 0.22 \\
Lactation 1,3 & $0.57 \pm 0.52$ & $0.10 \pm 0.04$ & 0.23 \\
Lactation 2,3 & $0.67 \pm 0.32$ & $0.53 \pm 0.03$ & 0.58 \\
\hline
\end{tabular}

Genetic correlation $\left(\mathrm{r}_{\mathrm{G}}\right)$ estimates across lactations were positive and moderate, ranging from 0.56 to 0.67 , table 3 . The strongest genetic correlation was between the second and the third lactation, (0.67). These estimates suggest that RP are not possibly the same trait across the first three lactations.

Comparable ranges of $r_{\mathrm{G}}$ among the three lactations were reported by Heringstad et al. (2005). Reported estimates were 0.55 between first and second lactation, 0.59 between first and third lactation and 0.65 between second and third lactation, indicating that the strongest $r_{G}$ were between the second and third lactations. Higher estimates of $r_{G}$ were reported by Haugaard and Heringstad (2015) on the first 5 lactations. The authors reported $r_{G}$ of 0.69 between first and second, 0.60 between first and third and 0.92 between second and third lactation, respectively. Also, Schnitzenlenhner et al. (1998) reported $\mathrm{r}_{\mathrm{G}}$ of 0.79 between first and second lactations.

Environmental proportion had a decreasing trend from the first, (0.77) to the third lactation, (0.69) and environmental correlation between the second and the third lactation was the highest (0.53), table 3 . This finding indicates that environmental conditions affect the early lactations more than later. Hauggard and Heringstad (2015) reported lower environmental correlations between lactations ranging from -0.05 to 0.19. Phenotypic correlations shown in table 3 ranged from 0.22 to 0.58 and it was higher between the second and third lactations than between other lactations.

\section{Genetic, environmental and phenotypic (co)variance structures for Stillbirth:}

Table 4 shows an increasing trend of the direct genetic variance (from 6.87 to 9.09 ) across the three lactations, while the maternal variance component decreased from the first to the second lactation.

Direct genetic variance increased by $4 \%$ from the first to the second lactation (6.87 to 7.14) while increased by $27 \%$ from the second to the third lactation. Maternal genetic variance decreases by $13 \%$ from the first to the second lactation (9.82 to 8.56) while increased by $3 \%$ from the second to the third lactation. 
Table 4. Direct and maternal genetic (co)variances among the first three lactations for SB

\begin{tabular}{lcc}
\hline Lactation & Direct & Maternal \\
\hline Lactation 1 variance & 6.87 & 9.82 \\
Lactation 2 variance & 7.14 & 8.56 \\
Lactation 3 variance & 9.09 & 8.82 \\
& & \\
Lactation 1,2 covariance & 4.41 & 10.29 \\
Lactation 1,3 covariance & 3.31 & 6.44 \\
Lactation 2,3 covariance & 5.77 & 8.54 \\
\hline
\end{tabular}

The direct genetic components were lower than the maternal components. This finding was in agreement with Heringstad et al. (2007) findings in which the authors reported a direct genetic variance component of 0.079 and a maternal component of 0.082 and with Cole et al. (2007b) where mean direct sire variance was 0.009 and the MGS variance was 0.018. Eaglen et al. (2012) comparing first $v$ s second and third parities, reported 0.002 for direct genetic variance component in the first parity with 0.002 for the maternal component.

Direct and maternal covariance components between the first and second lactation was higher than that between first and the third lactation, table (4). The highest direct genetic covariance component was between the second and third lactation, while the highest maternal covariance was between the first and second lactation.

Table 5. Direct and maternal heritability $\left(h^{2}\right)$ estimates and genetic correlations $\left(r_{G}\right)$ among the first three lactations for SB

\begin{tabular}{lcc}
\hline Lactation & Direct & Maternal \\
\hline Lactation $\mathbf{1} \mathbf{h}^{2}$ & $0.28 \pm 0.05$ & $0.39 \pm 0.08$ \\
Lactation $\mathbf{2} \mathbf{h}^{\mathbf{2}}$ & $0.25 \pm 0.05$ & $0.34 \pm 0.06$ \\
Lactation $\mathbf{3} \mathbf{h}^{\mathbf{2}}$ & $0.23 \pm 0.05$ & $0.35 \pm 0.06$ \\
& & \\
$\mathbf{r}_{\mathbf{G ~ 1 , 2}}$ & $0.63 \pm 0.06$ & $0.68 \pm 0.05$ \\
$\mathbf{r}_{\mathbf{G 1 , 3}}$ & $0.42 \pm 0.08$ & $0.36 \pm 0.07$ \\
$\mathbf{r}_{\mathbf{G ~ 2 , 3}}$ & $0.71 \pm 0.08$ & $0.46 \pm 0.07$ \\
\hline
\end{tabular}

The additive genetic variance due to direct effects was smaller than that due to maternal effects and direct heritability estimates were also smaller than those of maternal heritability. Direct heritability estimates, table 5 were $0.28,0.25$ and 0.23 for the first three lactations, respectively, taking a decreasing trend. This trend is in agreement with Swalve et al., (2006) who reported higher $\mathrm{h}^{2}$ estimate of maternal effect than the direct $h^{2}(0.29$ vs. 0.147) for first parity Holstein data with sire-MGS model, and also with Eaglen et al. (2012) for first parity estimates (0.024 vs. 0.016). Higher estimates for maternal effect are in agreement also with Heringstad et al. (2007), (0.08 and 0.07), Hansen et al. (2004), (0.12 and 0.10). Wiggans et al., (2008) on Holstein cattle, reported lower direct sire heritability estimates than MGS heritability estimates in both first and later parities. Liu et al. (2012) reported decreasing trend of heritability estimates for the first three lactations, (0.027, 0.008 and 0.006) for direct $h^{2}$ estimates and (0.054, 0.006 and 0.005) for maternal $h^{2}$ estimates. Abdelharith and Genena, (2017) reported heritability estimates for SB from 0.18 to 0.32 using different models on the same Friesian herd under this study.

Direct genetic correlation estimates $\left(\mathrm{r}_{\mathrm{G}}\right)$ between lactations are shown in table 5. The direct estimate between the second and the third lactation (0.71) was the highest, while the highest maternal genetic correlation was between the first and second lactation, (0.68). All estimates of $r_{G}$ were positive, moderate and were in range of estimates reported by Liu et al. (2012). Hossein-Zadeh (2011) reported smaller $\mathrm{r}_{\mathrm{G}}$ estimates on Iranian Holstein, (0.08 and .12) for in between first and third and between second and third lactations, respectively. From the resulted direct and maternal heritability estimates and genetic correlations, it can be determined that genetic improvement could be achieved and also that SB is not the same trait in the first three lactations.

Regarding the direct-maternal relationships, the results show that all genetic covariance components between direct and maternal effects were all positive, and direct-maternal genetic correlation estimates among them (results not shown in tables) ranging from 0.20 to 0.75 . These positive genetic correlations suggest that selecting sires against occurrence of stillbirth will be in the same direction of his daughters which will help in the selection process and in the breeding programs. The positive genetic correlations could be expected because a part of the direct effect of bulls is also a part of the MGS effect. The genetic correlation between direct and maternal effects were larger than those negative small estimates reported by Swalve et al. (2006), (-0.46), Heringstad et al. (2007), (-0.02) in Norwegian Red cows and Liu et al., (2012) on German Holstein. Cole et al. (2007b) and Eaglen et al., (2012) reported positive moderate $r_{G}$ estimates between direct and maternal effects, (0.33 and 0.567$)$, respectively.

Table 6 shows the proportions of the environmental variances and correlations. A very small proportion of variances ranging from 0.03 to 0.04 were obtained. High environmental correlations among the three lactations were found ranging from 
0.86 to 0.89 . These positive estimates are higher than those estimated by Liu et al., (2012), (0.02, 0.01 and
0.02) for in between first and second, first and third and second and third lactation, respectively.

Table 6. Environmental (Env.) and phenotypic (Pheno.) (co)variances, their proportions (Prop.) and correlations $\left(r_{E}, r_{P}\right)$ for $S B$ in the first three lactations

\begin{tabular}{lcccc}
\hline Lactation & Env. Var. & Env. Prop. & Pheno. Var. & Pheno. Prop. \\
\hline Lactation 1 & 1.0 & $0.04 \pm 0.01$ & 25.19 & 1.0 \\
Lactation 2 & 1.0 & $0.03 \pm 0.00$ & 29.02 & 1.0 \\
Lactation 3 & 1.0 & $0.03 \pm 0.00$ & 39.65 & 1.0 \\
& Env. Cov. & $\mathbf{r}_{\mathbf{E}}$ & Pheno. Cov. & $\mathbf{r}_{\mathbf{P}}$ \\
Lactation 1,2 & 0.87 & $0.87 \pm 0.00$ & 21.25 & 0.79 \\
Lactation 1,3 & 0.86 & $0.86 \pm 0.00$ & 16.29 & 0.52 \\
Lactation 2,3 & 0.89 & $0.89 \pm 0.01$ & 21.28 & 0.63 \\
\hline
\end{tabular}

Phenotypic variance of SB had an increasing trend from the first to the third lactation, table 6 . This increase could be referred to changes in herd management and other environmental and nutrition conditions. Phenotypic covariance between the second and third lactation (21.28) was the highest covariance component. Eaglen et al., (2012) reported a lower phenotypic component of 0.096 for the first lactation. Phenotypic correlations, (table 6) were higher between first and second lactation (0.79) than those between other lactations. As shown from the estimated correlations, the environmental correlations were higher than the direct and maternal genetic correlations.

\section{Breeding values and rank correlations:}

Table 7 shows means of predicted breeding value estimates for RP sires in the first three lactations. All means of estimates were near zero with negative sign. Range of estimates in the first lactation evaluation was between -0.477 and 0.558 and range of estimates for the second lactation was between 0.148 and 0.595 . Estimates of the third lactation ranged between -0.789 and 1.397. High standard deviation estimates in the three lactations explain that there is lack of variation between estimates.

Table 7. Breeding value means of sires and standard deviation (Std) for RP

\begin{tabular}{lllll}
\hline Lactation & $\mathbf{N}$ & Minimum & Maximum & Mean(Std) \\
\hline $\mathbf{1}$ & 141 & -0.477 & 0.558 & $-0.002(0.15)$ \\
$\mathbf{2}$ & 141 & -0.148 & 0.595 & $-0.001(0.16)$ \\
$\mathbf{3}$ & 141 & -0.789 & 1.397 & $-0.005(0.29)$ \\
\hline
\end{tabular}

From the means showed in table 7 , it can be revealed that no deterioration for RP trait in the herd. Rank correlation was applied for sires utilized in the
RP analysis, table 8. All correlation coefficients were positive and moderate.

Table 8. Rank correlation coefficients among the BVs of RP Sires in the first three lactations.

\begin{tabular}{lcc}
\hline Lactations & $\mathbf{N}$ & RP breeding values rank correlation $*$ \\
\hline $\mathbf{1 , 2}$ & 141 & $0.69(0.0001)$ \\
$\mathbf{1 , 3}$ & 141 & $0.68(0.0001)$ \\
$\mathbf{2 , 3}$ & 141 & $0.56(.0001)$ \\
\hline
\end{tabular}

*Level of significance in brackets

The correlation between the first and the second lactation was significantly correlated with 0.69 , and the lowest correlation estimate was between the second and the third lactation, 0.56. Significant estimates of rank correlation might suggest that some sires differ in ranking from one lactation to another which require multiple evaluation.

As shown in table 9, all means of predicted breeding value estimates of direct and maternal SB evaluations are negative. Estimates of sires' breeding values ranged from -1.083 to -0.995 in the direct evaluation and ranged from -1.155 to -0.900 in the maternal evaluation. The direct evaluation estimates of MGS ranged from -1.444 to -0.499 and the maternal evaluation from -2.477 to -0.971 . The negative estimates suggest that good practices for SB in the herd are followed properly.

Table 9. Breeding value means and standard deviations (in brackets) of sires and MGS for SB in both direct and maternal evaluations

\begin{tabular}{lcccccc}
\hline Lactation & \multicolumn{2}{c}{ Sires } & \multicolumn{2}{c}{ MGS } \\
\hline & $\mathbf{N}$ & Direct & Maternal & N & Direct & Maternal \\
\hline $\mathbf{1}$ & 125 & $-0.995(2.24)$ & $-0.982(2.65)$ & 147 & $-0.499(1.22)$ & $-2.477(2.78)$ \\
$\mathbf{2}$ & 125 & $-1.030(2.28)$ & $-1.155(2.34)$ & 147 & $-1.020(1.22)$ & $-1.871(3.33)$ \\
$\mathbf{3}$ & 125 & $-1.083(2.67)$ & $-0.900(2.39)$ & 147 & $-1.444(1.88)$ & $-0.971(4.46)$ \\
\hline
\end{tabular}


Table 10 shows the rank correlation coefficients among the three lactation' estimates for both sires and MGS. For the sires, the rank correlation of the maternal evaluation was higher than the direct evaluation ranging from 0.81 to 0.93 . On the contrary, for MGS, the rank correlation in the direct evaluation was higher than those of the maternal evaluation. Significant differences in ranking of sires indicate the importance of utilizing multiple evaluation of sires in different lactations.

Table 10. Rank correlation coefficients among the BVs of SB for sires and MGS in the first three lactations.

\begin{tabular}{|c|c|c|c|c|}
\hline \multirow[t]{2}{*}{ Lactations } & $\begin{array}{c}\text { SB } \\
\text { Direct } \\
\text { Evaluation }\end{array}$ & $\begin{array}{c}\text { SB } \\
\text { Maternal } \\
\text { Evaluation }\end{array}$ & $\begin{array}{c}\text { SB } \\
\text { Direct } \\
\text { Evaluation }\end{array}$ & $\begin{array}{c}\text { SB } \\
\text { Maternal } \\
\text { Evaluation }\end{array}$ \\
\hline & \multicolumn{2}{|c|}{ Sires $(\mathrm{N}=125)$} & \multicolumn{2}{|c|}{ MGS $(N=147)$} \\
\hline 1,2 & $0.55(0.0001)$ & $0.81(0.0001)$ & $0.59(0.0001)$ & $0.49(0.0001)$ \\
\hline 1,3 & $0.24(0.01)$ & $0.93(0.0001)$ & $0.55(0.0001)$ & $0.26(0.0001)$ \\
\hline 2,3 & $0.62(0.0001)$ & $0.86(0.0001)$ & $0.97(0.0001)$ & $0.41(0.001)$ \\
\hline
\end{tabular}

*Level of significance between brackets

\section{CONCLUSIONS}

Estimates of genetic, environmental and phenotypic (co)variance structures for RP and SB in the first three lactations could be obtained. The utilized multi-parity analysis could be followed for RP and SB traits as it accounted for the variations among the lactations and should increase the evaluation accuracy since the genetic correlations between lactations are less than one for both traits. Moderate heritability estimates For RP and SB with the frequency of incidence make the selection against these traits and genetic improvement possible. Genetic correlation estimates indicate that RP and SB cannot be regarded as the same trait in the first three lactations. Negative means of predicted breeding values for RP and SB indicate that these traits are not declining in the herd. Significant differences in the ranking of sires among the first three lactations in both RP and SB indicate the importance of the multiparity evaluation of sires in different lactations.

\section{REFERENCES}

Abdelharith, Hanaa and Shereen K. Genena, 2017. Associations between functional traits and milk production in Friesian cattle using threshold and linear models. Egyptian J. Anim. Prod., 2017 54(1):9-16.

Amin A.A, T. Gere and W.H. Kishk, 2000. Additive genetic variance and covariance in some reproductive disorders in Hungarian Holstein Friesian using multi-trait animal model. Arch Tierz 43, 573-81.

Cole J. B., Wiggans G. R. and P. M. VanRaden, 2007a. Genetic evaluation of stillbirth in United States Holsteins using a sire-maternal grandsire threshold model. J. Dairy Sci. 90:2480-2488

Cole J. B., Wiggans G. R., VanRaden P. M. and R. H. Miller, 2007b. Stillbirth (co)variance components for a sire-maternal grandsire threshold model and development of a calving ability index for sire selection. J. Dairy Sci. 90:2489-2496.
Eaglen S. A. E., Coffey M. P., Woolliams J. A. and E. Wall, 2013. Direct and maternal genetic relationships between calving ease, gestation length, milk production, fertility, type, and lifespan of Holstein-Friesian primiparous cows. J. Dairy Sci. 96:4015-4025.

Eaglen S.A.E., Coffey,M.P, Woolliams J. A. and E Wall1, 2012. Evaluating alternate models to estimate genetic parameters of calving traits in United Kingdom Holstein-Friesian dairy cattle. Genetics Selection Evolution 2012, 44:23.

Eaglen S.A.E., Coffey M.P., Woolliams J.A, Mrode R. and E. Wall, 2011. Phenotypic effects of calving ease on the subsequent fertility and milk production of dam and calf in UK HolsteinFriesian heifers. J Dairy Sci. 2011, 11:54135423.

Hansen, M., M. S. Lund, Pedersen, J. and L. G. Christensen, 2004. Genetic parameters for stillbirth in Danish Holstein cows using a Bayesian threshold model. J. Dairy Sci. 87:706716.

Haugaard K. and B. Heringstad, 2015. Short communication: Genetic parameters for fertilityrelated disorders in Norwegian Red. J. Dairy Sci. 98:1321-1324.

Heringstad B., Chang Y. M., Gianola D. and G. Klemetsdal, 2005. Genetic analysis of clinical mastitis, milk fever, ketosis, and retained placenta in three lactations of Norwegian Red Cows. J. Dairy Sci. 88:3273-3281.

Heringstad B., Chang Y. M., Svendsen M. and D. Gianola, 2007. Genetic analysis of calving difficulty and stillbirth in Norwegian Red Cows. J. Dairy Sci. 90:3500-3507.

Heringstad, B., 2010. Genetic analysis of fertilityrelated diseases and disorders in Norwegian Red cows. J. Dairy Sci. 93:2751-2756.

Hossein-Zadeh, N. G., 2011. Estimation of genetic parameters and genetic change for stillbirth in Iranian Holstein cows: a comparison between linear and threshold models. Agric. And Food Sci., 20:287-297. 
Koeck A., Miglior F., Jamrozik J., Kelton D. F. and F. S. Schenkel, 2014. Genetic relationships of fertility disorders with reproductive traits in Canadian Holsteins. Proceedings, $10^{\text {th }}$ World Congress of Genetics Applied to Livestock Production.

Lin H. K, Oltenacu P. A. and L. Dale Van Vleck, 1989. Heritabilities of and genetic correlations among six health problems in Holstein cows. J. Dairy Sci. 72:180-186.

Liu Z., Pasman E., Reinhardt F. and R. Reents, 2012. A multi-parity animal model for genetic evaluation of calving traits enhanced with genomic information. INTERBULL BULLETIN NO. 46. Cork, Ireland, May 28 - 31, 2012.

Philipsson, J. and L. Steinbock, 2003. Definition of calving traits-Studies from Swedish research. Interbull Bulletin 30:71-74.

SAS, I., 2009. What's New in SASs 9.2. Cary, SAS Institute Inc.,NC.

Schnitzenlehner, S., A. Essel and J. Solkner, 1998. Retained placenta: Estimation of nongenetic effects, heritability and correlations to important traits in cattle. J. Anim. Breed. Genet. 115:467478.

Steinbock, L., A. Na“sholm, B. Berglund, Johansson, K. and J. Philipsson, 2003. Genetic effects on stillbirth and calving difficulty in Swedish Holsteins at first and second calving. J. Dairy Sci. 86:2228-2235.

Swalve H. H., Schafberg R. and F. Rosner, 2006. Genetic parameters for categories of stillbirth in dairy cattle. 8th World Congress on Genetics Applied to Livestock Production, August 13-18, 2006, Belo Horizonte, MG, Brazil.

Van Tassel, C.P. and L.D.Van Vleck, 2001. A manual for use of MTGSAM. A set of fortran programs to apply Gibbs sampling to animal models for variance component estimation, last revised 2001, Department of Agriculture, Agricultural Research Service, Nebraska, USA.

Wiggans G. R., Cole J. B. and L. L. M. Thornton, 2008. Multiparity evaluation of calving ease and stillbirth with separate genetic effects by parity. J. Dairy Sci.:91:3173-3178.

\section{بناء التغايز والمقاييس الور اثية لصفات احتباس المثيمة و الولادة النافقة لقطيع من الفريزيان باستخدام نماذج سلمية متعددة المواسم التغاير المع هناء عبدالحارث}

\section{معط بحوث الإنتاج الحيوانسي، مركز البحوث الزراعية، اللقي،الجيزة، مصر}

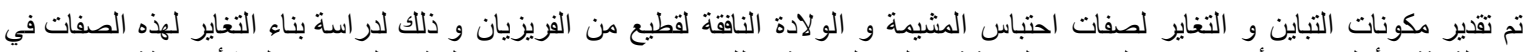

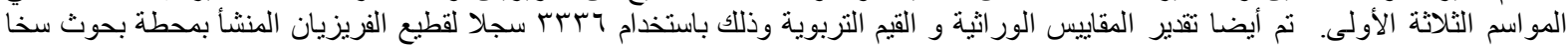

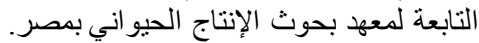

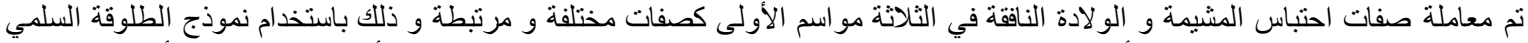

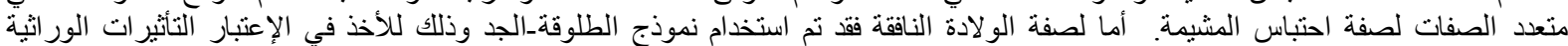

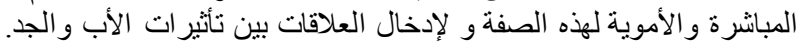

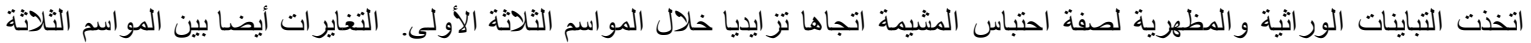

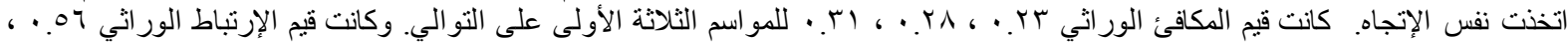

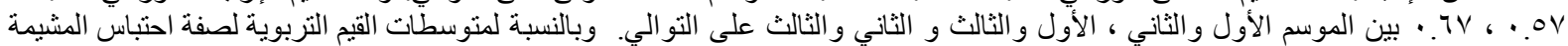

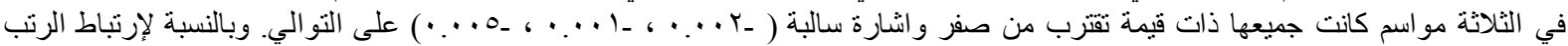

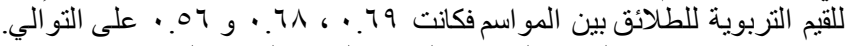

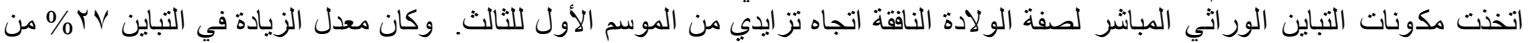

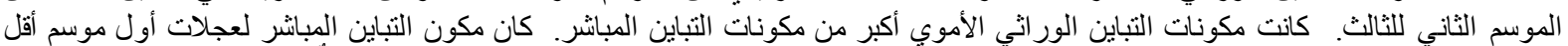

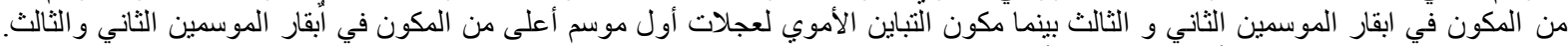

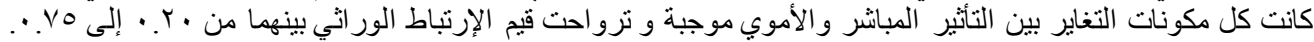

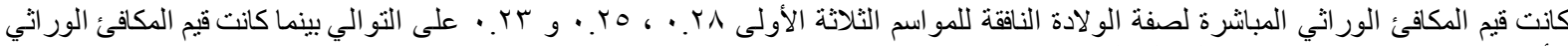

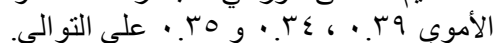

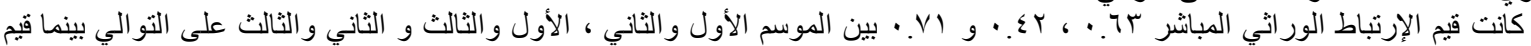

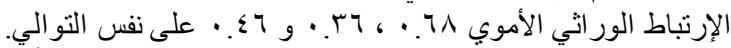

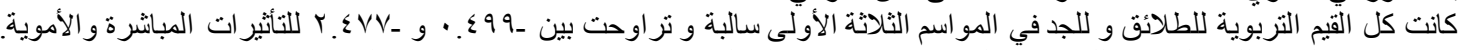

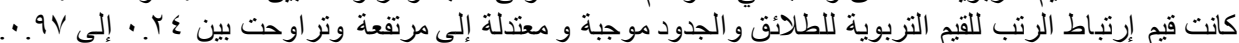

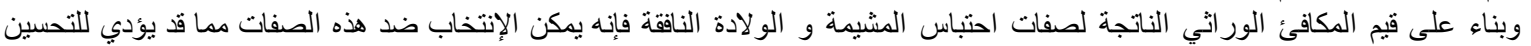

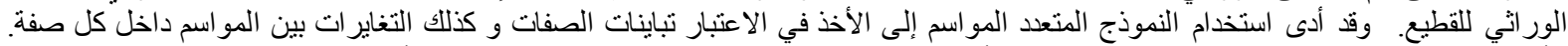

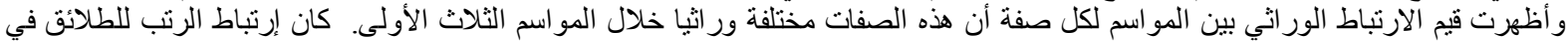

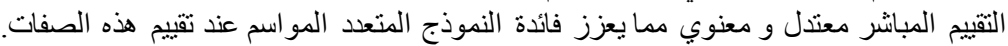

